\title{
O ESPAÇO DA VIDA: UM ESTUDO BIOGEOGRÁFICO*
}

\section{FRIEDRICH RATZEL*}

VERLAG DER H. LAUPP'SCHEN BUCHHANDLUNG

TÜBINGEN, 1901

Extraído de Caderno comemorativo para Albert Schäffle por seu septuagésimo aniversário, p. 101-189.

Publicado também como brochura independente no mesmo ano e pela mesma editora. 87p.

\section{SUMÁRIO}

A VIDA E O ESPAÇO TERRESTRE.

.P. $2 / 104$

A MUTABILIDADE DA SUPERFÍCIE TERRESTRE E O DESENVOLVIMENTO DA VIDA.

O ENFRENTAMENTO ESPACIAL COMO ATRIBUTO DA VIDA 
[p. $1 / 103]^{1}$ As condições de todo desenvolvimento da vida são governadas por uma grande força telúrica. Mesmo quando os casos singulares parecem ser mediados puramente no âmbito local, à medida que penetramos mais profundamente, encontramos raízes que estão imersas nas propriedades fundamentais do planeta.

Destarte, não somos da opinião de que a história de todas as espécies vegetais e animais e todas as nações e Estados deva ser colocada em uma base cosmológica, tal como fora realizada, certa vez, a história do país e da cidade que surgiu com a criação do mundo. Mas assim como em nossa época a exigência de Herder começa novamente a ser compreendida, qual seja, a de que a filosofia da história humana deveria descer do céu estrelado, do mesmo modo devemos impor a exigência para a Biogeografia, incluindo-se aí a Antropogeografia, de que ela parta da Terra inteira. Toda existência terrena repousa sobre a mesma lei; desde a maior até a mais ínfima [existência], [tudo] está atrelado às propriedades fundamentais do planeta. A vida animada não considera a Terra muito grande quando a circunscreve nos imensos intervalos de tempo que ela precisa para o seu desenvolvimento, e toda forma de vida, até a de ocorrência mais limitada, tem congênere em partes remotas da Terra. $\mathrm{Na}$ história de cada planta da família da hortelã que habita apenas alguns prados alpinos da Caríntia ${ }^{2}$, de cada insetívoro que esteja restrito a um alto vale dos Pireneus, ou da menor tribo de anões ${ }^{3}$ na selva africana residem os efeitos do tamanho e forma, dos movimentos, massa e composição material do globo inteiro.

\section{[P. 2 / 104] A VIDA E O ESPAÇO TERRESTRE}

0 que quer que seja que almeje espaço [Raum] na Terra, terá de se criar nos limitados 506 milhões de quilômetros quadrados da superfície terrestre [Erdoberfläche]. Este número é, portanto, a primeira grandeza espacial [Raumgröße] com a qual a história da vida teria a ver, bem como também a última. Dentro dela estariam encerradas todas as demais grandezas; nela todas as demais grandezas seriam mensuradas, estando nela dados os limites absolutos de toda vida corpórea. Essa grandeza é praticamente imutável para a história da humanidade, mas ela não pode ser pensada como completamente

'Apresenta-se aqui, primeiramente, a paginação que consta na publicação independente, seguida da paginação do artigo que compõe a coletânea em homenagem aos 70 anos de vida de Albert Schäffle, onde foi publicado originalmente. [N.T.]

${ }^{2}$ Caríntia é o estado mais ao sul da República da Áustria. [N.T.]

3É o modo como se refere aos Pigmeus [N.T.] imutável para a história da Terra [Erdgeschichte] e de sua vida em geral. Que a Terra tenha sido maior no passado e encolhido devido ao resfriamento, nisso acreditam muitos geólogos; e que a Terra tenha aumentado por meio de colisão de meteoritos, parece-nos visível a olho nu. Mas, provavelmente, nem aquele encolhimento, nem essa ampliação seriam tão consideráveis, a ponto de a vida, cuja história poderíamos negligenciar, ter sido transformada por eles de maneira notável. Ambos os processos, contração e expansão da Terra, são extremamente difíceis de serem investigados por causa da extensão do espaço de tempo no qual eles se realizaram, e quase não se pode esperar que se dissemine clareza sobre isso num futuro previsível. De qualquer modo, não cometemos nenhum grande erro se aceitarmos, de antemão, que o desenvolvimento da vida tenha tido como fundamento, no período que negligenciamos, o mesmo espaço terrestre [Erdraum] que hoje em dia. Pois ainda que a contração por resfriamento e por encolhimento possa ser comprovada, o que ainda é muito questionável, a expansão paulatina por meio da colisão de massas cósmicas é de fato certa. Ambos os efeitos poderiam, portanto, se anular mutuamente. Ainda que devamos ter em mente que o espaço terrestre [Erdraum] não tenha sido o mesmo em todos os períodos da história da Terra [Erdgeschichte], deveríamos mesmo continuar [p. 3 / 105] a aceitar que ele tenha permanecido essencialmente o mesmo num único e mesmo período. Não temos, por exemplo, nenhuma razão para aceitar que, na parte da história da Terra [Geschichte der Erde], da qual nos são legados testemunhos da vida em fossilizações, tenha se realizado uma transformação essencial do espaço terrestre [Erdraum]. 0 autor da obra "Challenger", John Murray4, pôde de fato responsabilizar um sol maior pela ocorrência de corais construtores de recifes em mares silurianos da zona polar do sul; todavia, nenhum naturalista de similar autoridade jamais transmitiu essa audácia de fantasia constitutiva de hipótese - que extrapola o âmbito da poesia - a outro capítulo da história da Terra [Geschichte der Erde]. Em nossa investigação, portanto, permaneçamos partindo de um espaço terrestre [Erdraum] que, com extensão essencialmente igual, está na base da vida mutável enquanto uma grandeza constante.

A limitação de todo o desenvolvimento da vida da Terra a um único e mesmo espaço [Raum] significa a concentração, nos estritos limites desse espaço terrestre [Erdraum], de todos os fenômenos internos da vida e de todas as influências externas que a vida experimen-

4John Murray (1841-1914), naturalista e oceanógrafo britânico, participou da primeira expedição marítima global entre 1872 e 1876. Publicada em 50 volumes, sua obra estabeleceu as bases da Oceanografia. [N.T.] 
ta. Assim como em um líquido fermentante, a natureza do produto depende do fato de todo o processo de fermentação realizar-se no espaço estrito de um recipiente fechado ou ao ar livre, sob interação permanente com o ar e a água, também o desenvolvimento da vida da Terra é determinado principalmente por seu confinamento [Abgeschlossenheit]. Embora a vida sempre surja contra essas barreiras, ela não as quebra, pois está atrelada à Terra. Forçada a revolver, ela deve permanentemente percorrer velhos caminhos. Sob essas condições espaciais [Raumbedingungen], o desenvolvimento da vida se torna um processo de somatório. Na vida da Terra reside a soma das influências telúricas, solares e cósmicas que se acumularam, se interpenetraram, combateram entre si e se intensificaram, [p. 4 / 106] desde o momento da primeira germinação da vida até os dias atuais. Também as partes inorgânicas da Terra são explicadas por muitos como a consequência de massas cósmicas que colidiram, mas esse processo de somatório permite, como todos os outros [processos] inorgânicos, que as matérias coexistam inalteradas, ou que elas no máximo se reduzam a ligações simples, ao passo que a vida produz progressivamente ligações a partir de matérias-primas novas e mais complexas, progredindo, por meio de pequenas modificações, para formas cada vez mais novas, mais complexas, melhor adaptadas e, portanto, mais eficazes e mais eficientes. Enquanto uma propriedade fundamental da vida no espaço relativamente estreito de nosso planeta, a propriedade da variabilidade atua intensificando, impulsionando adiante as formas de vida. A mudança brusca de influências externas, o contato mais estreito de forma de vida com forma de vida, que conduz a compensações, ajustes, deslocamentos e novas formações, se dá, portanto, devido à estreiteza do espaço terrestre [Erdraum].

\section{A MUTABILIDADE DA SUPERFÍCIE TERRESTRE E O DE- SENVOLVIMENTO DA VIDA}

Nos limites de sua extensão invariável, a superfície terrestre [Erdoberfläche] experimenta permanentemente reformulações.

Evidentemente, fala-se mais de mutabilidade da vida do que de mutabilidade do solo [Boden], do qual a vida depende, porque esta [vida] é ligada àquele [solo]. A variabilidade da matéria animada é um dos princípios da doutrina da vida; todavia, que uma parte dessa variabilidade seja deflagrada apenas pela mudança das condições de vida [Lebensbedingungen] que dependem do solo [Boden], é, do ponto de vista prático, muito menos aceito, ainda que ninguém possa duvidar disso na teoria.
As propriedades internas [p. 5 / 107] da Terra interagem com as influências dos astros para manter as condições telúricas da vida em ondulações ininterruptas. A grandeza do espaço da vida [Lebensraum] , a posição [Lage] e a extensão [Ausdehnung] das regiões climáticas, das terras e dos mares mudam constantemente e, com eles, as altitudes e profundidades da Terra. Em outras palavras: a mutabilidade do substrato da vida [Lebensgrundlage] recria constantemente as condições exteriores da vida [Lebensbedingungen]. Quando as mudanças da superfície terrestre [Erdoberfläche] são amplamente disseminadas e se repetem frequentemente no solo, nas águas e no clima de maneira suficientemente forte para intervir na esfera da vida [Lebenssphäre], elas devem exercer um grande efeito sobre o desencadeamento, bem como, ao mesmo tempo, sobre o direcionamento da mutabilidade do mundo animado. Acima de tudo, transformam-se os espaços [Räume] nos quais as mudanças ocorrem e novas formas se disseminam e se estabelecem, determinadas de acordo com a posição [Lage] e a grandeza [Größe]. Essas [mudanças] indicam novos habitats [Lebensgebiete], conectando-as e desconectando-as, abrindo-as e limitando-as. Não é paradoxal, ainda que pareça, dizer que as mudanças inorgânicas atuam no desenvolvimento orgânico não apenas estimulando, mas também dirigindo e estruturando. E se devemos estar preparados para considerar o espaço da vida [Lebensraum] ${ }^{5}$ de cada espécie ou raça como uma parte integrante de seu ser, devemos levar em conta as mudanças morfológicas e climáticas desse espaço [Raum] e remontar aos espaços [Räume] que seriam completamente diferentes dos de hoje em dia. Tende-se, muitas vezes, a apelar apenas à explicação da grandeza [Größe], da posição [Lage] e da forma [Gestalt] de uma área de difusão [Verbreitungsgebiet] de mudanças no clima e no solo quando todos os outros meios fracassam; a lógica exige, no entanto, que tais mudanças sejam tomadas como necessárias.

Em lugares da Terra onde, em um período que corresponderia a um passado na História da Terra, [cresciam] plantas tropicais, atualmente crescem plantas da zona temperada e, no futuro, a vida lá será reduzida à pequeneza e pobreza polares. Onde no passado era fundo de mar [p. 6 / 108], hoje é terra plana e, no futuro, será arqueado, dando origem a uma montanha a partir de dobramento. A montanha acabada desmoronará, afundará, fragmentar-se-á. Ainda mais comuns são os casos em que floresta e deserto, lago e estepe se transformam. É

${ }^{5} \mathrm{~A}$ fim de descolar o termo composto Lebensraum daquela conceituação que o tornou amplamente conhecido graças a sua instrumentalização pela Geopolitik de Kjéllen e Haushofer - termo este tradicionalmente vertido, nas mais variadas línguas, como "espaço vital" -, optou-se aqui por sua tradução como "espaço da vida". Com esta tradução procura-se, portanto, dar ênfase ao seu sentido originário, cuja raiz remonta à Biogeografia, tal como expresso no próprio subtítulo do presente artigo. [N.T.] 
verdade que essas transformações se processam vagarosamente; mas o seu ritmo não é tão lento a ponto de nós estarmos em condições de compreender a história de alguma das raças humanas que atualmente povoam a Terra sem a consideração das mudanças da superfície terrestre [Erdoberfläche] ocorridas no decorrer de sua existência. As raças da Europa surgiram em uma Europa que não conhecia os mares do Norte e Báltico, nem a extensão atual do Mediterrâneo, e ainda menos a ampla ligação entre a Europa e a Ásia, que é característica hoje do continente duplo. E em seu desenvolvimento talvez tenham interagido povos de maneira muito mais decisiva do que suspeitamos, os quais habitavam terras férteis no norte da África e na Ásia ocidental e central que hoje são desertos.

Quando a natureza de um espaço [Raum] se reestrutura, este também se transforma sempre enquanto espaço da vida [Lebensraum]. Com a mitigação do clima após a era glacial na zona entre o Polo Norte e o paralelo $45^{\circ}$, os habitats [Lebensgebiete] das plantas e dos animais do Ártico estendidos por toda sua latitude contraíram-se e dividiram-se; as plantas e os animais do Ártico, que anteriormente ocupavam toda a região [Gebiet], restaram apenas lá onde suas condições de vida [Lebensbedingungen] permaneceram conservadas: no Ártico e nas altas montanhas. 0 caso oposto ocorreu antes da era glacial, quando o clima dos países nórdicos, no final do terciário, tornou-se mais violento e, ao mesmo tempo, ocorreram subsidências de terra; naquela época, os espaços da vida [Lebensräume] daqueles que habitavam em um clima quente se estreitaram e, no solo que restou, a vida encontrou cada vez menos espaço [Platz] entre a neve-firn e a geleira. Nesse caso, o número de organismos vivos em [S. 7 / 109] uma determinada área [Fläche] é o primeiro a recuar, mas também cai, com isso, o número de espécies, gêneros e famílias no decorrer do tempo, dando origem ao estado de pobreza de indivíduos e espécies, estado esse em que predomina hoje a vida do Ártico.

A aniquilação completa de toda a vida em uma ampla área não parece, no entanto, ser aceitável nem mesmo no caso da era glacial. Embora ninguém duvidasse que há algumas décadas o fogo, a água ou o gelo tivessem destruído temporariamente toda a vida em amplas regiões da Terra, nas quais, a partir do solo morto, uma nova vida tivesse origem, hoje em dia somos reticentes frente à catástrofe, mesmo no único caso em que algo do tipo parece possível. Claro que me refiro à era glacial. Existem mesmo pesquisadores da era glacial para os quais a antiga hipótese ainda é válida. James Geikie quase não admite um remanescente de vegetação até o sul da Inglaterra no auge da era glacial; somente quando o clima se tornou um pouco mais ameno é que teria sido ocupado por plantas e animais do Ártico. A destruição completa da fauna de borboletas da Europa setentrional e central durante a era glacial parece ainda ser amplamente aceita pelos lepidopterologistas. Hofmann só admite que teria sobrevivido um remanescente no extremo sul. Quadros semelhantes foram propostos por exploradores da fauna europeia de caracóis terrestres. Por outro lado, os botânicos se manifestaram mais decididamente contrários à [concepção da] destruição da vida na região glacial diluviana. De fato, se levarmos em consideração a difusão atual das plantas em um país como a Groenlândia -, que ficou tão completamente submersa no gelo que nem Inglaterra e Escócia jamais devem ter ficado, e considerando que neste país vive uma flora de 386 fanerogâmicas e criptogâmicas maiores, e certamente nos lugares protegidos em baías costeiras e em ilhas próximas às costas, muitas vezes numa diversidade e densidade quase exuberantes -, [p. 8 / 110] desse modo, não podemos defender, também para os países da Europa setentrional e central não cobertos pelo gelo diluviano, a fuga ou a destruição de toda a vida durante a era glacial. Nathorfte e, de maneira ainda mais contundente, Warming, atribuem a maior parte do mundo vegetal atual da Groenlândia a ancestrais que ali sobreviveram à era glacial. Quanto à Irlanda, Forbes já havia estabelecido um "elemento lusitano" na flora e na fauna, indicando uma conexão antiga com o sudoeste da Europa; outros pesquisadores também o encontraram na Inglaterra e no País de Gales. Recentemente, Kobelt defendeu até mesmo a sobrevivência de quase toda a fauna atual de caracóis terrestres da Europa central desde os tempos pré-glaciais.

Até o momento, tem sido dada muito pouca atenção ao fato de que a camada viva do solo teve que passar pelos movimentos do solo que a terra [Land] experimentou no sentido vertical. Onde hoje os Alpes soergueram nem sempre houve montanhas, ali existindo alternadamente ilhas, costas planas e região montanhosa. É mais do que provável que antigos elementos do mundo animado alpino tenham sofrido a transformação deste solo nas montanhas e altas montanhas. 0 espaço [Raum] permaneceu o mesmo com tais mudanças enquanto recorte da superfície terrestre [Ausschnitt der Erdoberfläche], mas suas propriedades intrínsecas se transformaram em grande medida elevada. De uma vasta área [Fläche] surge uma série de pequenas regiões [Kleingebieten] separadas, e de um espaço [Raum] com o mesmo clima tem origem uma justaposição de faixas climáticas [Klimagürtel], em que a mais superior divide a vida insular nas altas montanhas, até mesmo excluindo-a, em grande medida. Mudanças das condições de vida [Lebensbedingungen], como ocorrem aqui em um espaço [Raum] estrito, devem 
dar origem a novas formas de vida [Lebensformen] e, especialmente, nesse sentido, podemos falar das montanhas como centros de criação. Se imaginarmos a vida em uma área [Fläche] uniforme em equilíbrio com suas correspondentes condições uniformes, [p. 9 / 111] ao contrário, ela não poderá ser pensada senão como dividida, contraposta, impelida por movimentos orogênicos do solo e influenciada de maneira inteiramente diversa do ponto de vista climático.

No caso mais visível, o solo [Boden], que a cultura [Cultur] conquista e reformula, transforma sob nosso olhar as condições de vida [Lebensbedingungen] das espécies há muito estabelecidas nele, criando novas [condições] para o imigrante que traz cultura. Esses [imigrantes] se disseminam das antigas para as novas regiões de cultivo [Culturgebiete]. A Abissínia [atual Etiópia] tem uma série inteira de plantas silvestres cultivadas e ervas daninhas de origem mediterrânica, e elas ascendem a suas regiões de alta montanha. Como resultado, surgiram consonâncias muito mais abrangentes, pois a "Flora adventitia" das áreas de cultivo [Culturfläche] alemãs em campos e jardins também é, em grande parte, de origem mediterrânica. De modo semelhante, em todas as regiões de cultivo [Culturgebiete] tropicais a naturalização das assim chamadas ervas daninhas aumentou em muito o conjunto de espécies comuns a áreas remotas como a Índia, a África Oriental e as Antilhas. Soma-se a isso o grande número de plantas que cresceram escassamente em seu estado selvagem e agora estão experimentando repentinamente uma brutal difusão em terra cultivada. Desse modo, as florestas e pastagens da América do Norte e da América do Sul se tornaram ervas daninhas em nosso país.

A mais importante entre as propriedades mutáveis do espaço terrestre [Erdraum] é a sua composição de terra e água. Nele [espaço terrestre] se dividem componentes fluidos e fixos, cujas quantidades não permaneceram as mesmas em todos os períodos da história da Terra [Erdgeschichte]. Mas é certo que a divisão sempre existiu, em outras palavras, que em todos os períodos havia terras e mares, e que componentes secos e úmidos assumiram o espaço areal da Terra [Flächenraum der Erde] em todos os momentos. Uma vez que foram encontrados muitos testemunhos a favor do surgimento da vida a partir da umidade, [p. 10 / 112] houve, portanto, uma limitação inicial do espaço da vida [Lebensraum] na separação entre seco e úmido. Apenas a umidade originalmente abrigava a vida, tendo ela sido negada ao seco. E não há uma única razão - dentro do período de tempo que estamos examinando -, pela qual o globo terrestre [Erdball] tivesse sido uniformemente coberto de água. Ao contrário, as próprias diferenças entre as faunas silurianas indicam que existiam terras e ilhas, as quais dividiam o grande oceano em mares: as faunas do siluriano devem ter vivido em praias remotas de um continente onde elas tiveram muito pouco contato umas com as outras, tal como as do Atlântico médio e do Oceano Pacífico de hoje. Então, aqui já se mostra a grande característica da terra e da água de segregar regiões [Gebiete], cujo desenvolvimento da vida [Lebensentwicklung] continuou sempre se diversificando, de modo que a vida da terra [Leben des Lande] e a vida da água [Leben des Wassers] coexistem lado a lado como dois mundos que de fato se tocam, mas apenas como estranhos. A terra estreita o espaço da vida aquática [Raum des Wasserlebens], enquanto a água [estreita] o [espaço] da vida terrena [des Landlebens]. Mesmo para o homem que domina a água, enquanto habitante da terra, permanece a terra o elemento de morada. A Antropogeografia e a Geografia Política têm muito a dizer sobre o significado do mar na vida dos povos. Mas apenas os 135 milhões de milhas quadradas de terra (Land) são o solo da humanidade [Boden der Menschheit], a qual parte da terra [Land] em todos os seus movimentos e à terra [Land] retorna. 0 crescimento dos Estados se dá, acima de tudo, apenas neste estoque de 135 milhões de milhas quadradas de terra [Land] da Terra [Erde] atual.

Posto que terras e mares na Terra [Erde] se deslocaram ininterruptamente e ainda hoje se deslocam sob os nossos olhos, o espaço da vida [Lebensraum], tanto dos organismos aquáticos como dos [organismos] terrestres, está, portanto, permanentemente se transformando. Nem sempre o espaço terrestre [Erdraum] foi dividido entre eles de maneira tão desigual como hoje, onde a água recobre quase três vezes mais espaço [Raum] [p. 11 / 113] que a terra [Land]; mas sempre os habitantes da água e da terra tiveram de se distribuir na superfície terrestre [Erdoberfläche]. Então devemos imaginar, por exemplo, a imensa riqueza de formas de plantas e animais terrestres originada em uma área [Areal] de um quarto e, na melhor das hipóteses, de um terço da Terra [Erde]. Todavia, na concepção ainda hoje amplamente disseminada daqueles que admitem o surgimento da terra [Land] apenas no decorrer do período devoniano, os primeiros espaços [Räume] nos quais os primeiros organismos terrestres viviam, teriam sido ainda muito mais limitados. No entanto, consideramos essa concepção como um remanescente da limitada geologia catastrofista, deixado de pé por pura negligência. Pois a ausência de fósseis de organismos terrestres no período siluriano, isto é, logo acima das camadas antigas absolutamente desprovidas de fósseis, não prova que nenhuma terra [Land] tivesse se formado até então.

Se água e terra [Land] sempre existiram, também sempre existiram países [Länder] e mares grandes e 
pequenos. Pois na natureza da crosta terrestre [Erdrinde] reside o fato de que ela se movimenta em pequenas partes com a sedimentação, soerguimento e impulsão ou dobramento, de modo que todas as suas formas são constituídas de uma espécie de mosaico e algumas regiões [Länder] podem ser concebidas simplesmente como brecha ${ }^{6}$. A atual distribuição de terra [Land] no vasto mar é apenas uma das inúmeras que existiram anteriormente. Uma das maiores e mais belas tarefas da Geologia é reconstruir os continentes, ilhas e mares que existiram no passado. Hoje, impera uma espécie de divisão de terra [Landverteilung] que é caracterizada por um pequeno número de grandes continentes, algumas grandes ilhas e inúmeras ilhotas, passando pelo arranjo das maiores massas de terra em torno dos polos, que são por sua vez circundadas pelos mares contíguos do Norte e Sul. A divisão das terras firmes em três pares de continentes norte e sul, entre os quais existem três mares mediterrânicos, também pode ser descrita como uma característica [p. 12 / 114] da distribuição atual. Que tal [distribuição] nem sempre tenha sido assim e que, ao contrário, se transforme mesmo em períodos geológicos muito curtos, é comprovado pela juventude de tais formações, tais como o Mar do Norte, o canal [da Mancha], grandes partes do Mediterrâneo e do Mar Báltico que surgiram após o período terciário. Destarte, em cada período da história da Terra [Erdgeschichte], a vida na Terra trazia marcas da respectiva distribuição entre terra e água. $\mathrm{Na}$ atual distribuição da vida [Lebensverteilung], reconhecemos de maneira completamente evidente os traços daquela [distribuição] que a precedeu. Apenas um exemplo: os continentes meridionais nem sempre foram separados uns dos outros, e a Antártica nem sempre foi tão pobre de vida quanto é hoje. As araucárias da América do Sul e da Nova Zelândia, os marsupiais da América do Norte e da África do Sul, até mesmo animais menores habitantes da costa provam que os continentes meridionais já haviam sido conectados uma vez, e tornam provável que no hemisfério sul, de modo semelhante, a terra [Land] estava situada de maneira circumpolar, tal como é hoje no hemisfério norte.

\section{O ENFRENTAMENTO ESPACIAL COMO ATRIBUTO DA VIDA}

Quando falamos da mobilidade dos seres vivos, pressupomos o movimento como uma propriedade universal da vida. A vida é movimento que remonta continuamente a uma determinada forma; a vida é um somatório de

6Uma rocha clástica composta de fragmentos grandes e angulosos, unidas por material mais fino semelhante a uma massa de cimentação. [N.T.] movimentos internos desencadeados por estímulos externos; a vida é um metabolismo com uma forma constante: observa-se que em todas as definições da vida o movimento ganha destaque. Esta vida é então, em primeiro lugar, um fato interior do organismo. Contudo, a vida interior sempre vai gerar movimento exterior. Cada multiplicação da massa orgânica, cada crescimento, cada reprodução significa um movimento espacial [räumliche Bewegung]. E cada [p. 13 / 115] movimento é um enfrentamento espacial [Raumbewältigung]. Daí se desdobra uma porção de aplicações e interpretações geográficas. A ramificação de uma planta, o brotamento de um coral são dispersões espaciais [räumliche Ausbreitungen]. 0 germe de duas folhas do carvalho, que quase não ocupa nenhum espaço [Raum], transforma-se em uma árvore com milhares de folhas, cuja área de sombra pode ser medida em metros quadrados; um coral que vai se bifurcando e se interligando em padrão radial se transforma em um recife que cinge a costa leste australiana em 15 graus de latitude; o musgo germina ramos e estolhos e recobre, como pântano, uma área de milhares de quilômetros quadrados. Não poderíamos dizer que o enfrentamento espacial [Raumbewältigung] é um fenômeno geral da vida e uma marca da vida?

0 movimento da vida é abrangente. A fonte é móvel, mas sua água progride no sentido da gravidade, e o córrego que dela surge se movimenta inalteravelmente no mesmo fluxo e na mesma direção. O movimento da vida não é necessariamente dependente da gravidade; ele transborda em todas as direções, sua razão de ser reside no próprio organismo e os estímulos externos não são necessários para pôr em ação as forças orgânicas do movimento. 0 enfrentamento espacial [Raumbewältigung] tem na sequência das formas de vida seu desenvolvimento, ou melhor dizendo, seus desenvolvimentos que, através dos mais distintos meios, prestam significativo serviço em todos os grupos de seres vivos. Ao mesmo tempo, em todos os seres vivos conhecidos por nós, o movimento mais simples e mais primitivo, qual seja, o crescimento, torna-se distinto da mudança voluntária de lugar, que por fim envolve o movimento involuntário ou passivo com grandes efeitos. No caso das plantas e animais menores, a difusão ativa e passiva é facilitada precisamente pela simplicidade da constituição, a pequeneza, os estados de repouso, a simplicidade da dieta. Deste modo, encontramos as mesmas amebas em todas as partes do mundo e em água doce e salgada [p. 14 / 116]; poderíamos mover os infusórios ${ }^{7}$ tropicais para a Europa sem que o caráter da nossa fauna fosse altera-

7"Infusório" é um termo hoje superado, antigamente utilizado para identificar uma classe de protozoários de água doce. Hoje a maior parte de seus microorganismos são incluídos no reino denominado protista. [N. T.] 
do significativamente, e criar um plâncton a partir de um pequeno organismo quase congruente dos altos lagos alpinos e andinos.

Em níveis superiores, encontramos todos os mecanismos de movimento postos em ação, os quais poderiam vir a formar a matéria orgânica. Mesmo no caso dos infusórios, os cílios aparecem em movimentos muito rápidos, que então se repetem em todas as classes do reino animal, servindo, por fim, apenas para promover movimentos no interior dos organismos. Flagelos, bexigas natatórias, velas, provisões para ascender e imergir na água, aparatos para voar, rastejar, andar e escalar: a natureza experimentou de tudo, algumas coisas foram mantidas, muitas abdicadas, e tantas outras experimentaram um desenvolvimento em largura e altura. Os mecanismos de voo e caminhada dos pássaros e mamíferos estão entre os mais perfeitos que se pode imaginar. Além disso, a formação dos órgãos sensoriais e de muitos dos assim chamados instintos aponta para o mesmo objetivo dos mecanismos de movimento. Toda a estatura, a posição interna e o arranjo dos órgãos foram feitos a serviço do enfrentamento espacial [Raumbewältigung], que aparece em todos os níveis como objetivo principal das organizações. No próprio decorrer do desenvolvimento ele ganha destaque. As metamorfoses dos insetos e de muitos outros animais significam facilitação às migrações, na medida em que colocam o animal em um estado mais móvel em meios e oportunidades de dieta divergentes. Via de regra, a mudança de estadia e de dieta está ligada às metamorfoses. A lagarta pode estar ligada a uma determinada planta nutritiva, isto é, restrita em sua distribuição; a borboleta não está, mas sua difusão é limitada por sua dependência da lagarta. $\mathrm{Na}$ maioria dos casos, no entanto, o número e a variedade de condições de difusão aumentam [p. 15 / 117] graças a essas transformações. Também é provável que a maior mobilidade e independência da borboleta promova a adaptação da lagarta a novas plantas nutritivas. A lagarta não está, de modo algum, ligada de maneira tão escrava, como se costumava dizer. No Canadá, a papilio cresphontes migrou do sul por vários anos e buscou novas plantas nutritivas na família das rutáceas.

Diz-se que as tamaturacas ou stomatópodes que vivem no mar são muito favorecidas em sua difusão, de maneira incomum, devido à longa duração da condição larval. Pois as larvas são protegidas pela transparência e, ao mesmo tempo, dotadas de grande capacidade de movimentação. Essa união ocorre em muitos outros animais marinhos, de modo mais pronunciado nos equinodermos, cujas larvas bilateralmente simétricas, transparentes, móveis, parecem ser, à primeira vista, um grupo de animais muito diferente em relação aos equinoder- mos radiais, envoltos em conchas, fixados ou de difícil movimentação.

0 trichinella precisa emigrar se não quiser morrer com o animal em cujos músculos se encapsulou. 0 coral, se não tivesse uma juventude de aquecimento livre, continuaria sempre construindo no mesmo recife, onde muito cedo foram colocados limites à sua prosperidade. Alguém poderia talvez aceitar que um caracol terrestre, que viaja apenas alguns metros em toda a sua vida, constitua uma exceção; mas também ele procura alimento e proteção contra o frio e a aridez na medida em que migra. "A tendência de migrar é um importante e talvez o mais importante meio que a natureza emprega para impedir a extinção de uma nova espécie surgida" (Semper).

Ao lado de todas essas múltiplas provisões para a própria rápida movimentação, outros meios implicaram na formação, cujo [p. $16 / 118$ ] objetivo era a afirmação do lugar uma vez assumido e o progresso lento, seguro no seu entorno [Umgebung] próximo. Esses experimentaram seu maior desenvolvimento no reino vegetal, muito embora também o reino animal apresente toda uma série de formas, que se propagam lentamente a partir de um lugar onde estão estabelecidas. Somente algumas plantas inferiores se disseminam por esporos. Todas as demais se movem de maneira independente apenas em medida restrita, uma vez que elas, partindo de um lugar onde se fixam, espraiam raízes, produzem entrelaçamentos, formam ramificações. Por isso, no caso das plantas, o transportar e o ser conduzido desempenha um papel importante. Suas sementes e germes são muito mais adequados a isso do que os dos animais em geral. Que a simples dispersão por meio da disseminação da semente, o crescimento da raiz, a gemação alcance, a curto prazo, resultados consideráveis, isto fica provado por cada prado que se refloresta, e cada solo glacial esverdeado, cada clareira, que é recoberta em poucos anos com arbustos. Quando Junghuhn, em 1837, visitou com êxito o vulcão javanês apenas 14 anos após a terrível erupção que havia enterrado com lava fervente 114 aldeias, 4011 pessoas e 4 milhões de pés de café (em alguns lugares a lava deve ter chegado a atingir 15 metros de altura), para a sua grande surpresa ele encontrou o solo recém-vulcanizado "densamente recoberto por uma selva espessamente movimentada", no qual predominavam gramíneas, cavalinhas, zingiberales, samambaias, e a partir do qual se ergueram árvores de até 50 pés. No entanto, essa área está localizada em natureza tropical exuberante e uma grande fertilidade parece ser inerente à lava negra resultante.

Não apenas os menores seres vivos, tais como as diatomáceas, as bactérias, também os infusórios e os rotí- 
feros são portados pelo vento numa migração passiva; o vento também leva para longe os germes de plantas e animais maiores. A maioria [S. 17-119] das samambaias portadoras de esporos e os musgos da flora das ilhas oceânicas testemunha isso. Durante o reassentamento da ilha vulcânica de Krakatoa, após a erupção de 1883, os ventos exerceram um efeito mais forte do que as ondas. Eles carregaram esporos de samambaias e sementes de espermatófitas para o interior da ilha recém-formada ao longo de uma enseada de $20 \mathrm{~km}$ de largura, enquanto uma flora de praia de caráter bastante diferente emergia de lamaçais. As dezessete espécies que ocuparam a Ilha Krakatoa como as primeiras crias, pioneiras da vida, eram onze samambaias e dois musgos, ou seja, portadores de esporos, e quatro compostos que possuem sementes facilmente móveis. Quando se povoam piscinas naturais em estepes secas, poucos dias após a precipitação de chuva que as formou, com girinos, mexilhões e outros animais, pensa-se na observação de Marno no deserto da Núbia em que a fina crosta que se forma com a evaporação no lugar de tal piscina compreende uma massa de germes que seca, ganha volume com a poeira e desperta novamente à vida assim que é embebida de umidade. Onde os portadores de esporos contêm aparatos de centrifugação que ejetam os esporos no momento da maturação, o transporte será naturalmente facilitado. Os ventos são mais eficazes a distâncias mais curtas do que as ondas. Eles não só funcionam em um sentido horizontal, como também os ventos de montanhas e vales conectam em altitudes e profundidades. Além disso, o ar não é tão prejudicial à vida dos germes como a água e, especialmente, a água salgada.

Os ventos também levam animais maiores e germes de plantas. A observação de Darwin de que um pesado escaravelho voador, o Colymbetes, instalou-se em seu navio a $85 \mathrm{~km}$ da terra, o fato de que foram capturados no mar um pequeno serra-pau [p. 18 / 120] a $920 \mathrm{~km} \mathrm{e}$ gafanhotos a $370 \mathrm{~km}$ da costa da África Ocidental, mostram os efeitos do transporte eólico. Tal transporte também no caso dos animais é facilitado pelos meios mais variados. As teias de aranha, que vimos voar a mais de $100 \mathrm{~km}$ sobre o mar, são como balões de ar anões: em sua gôndola, que fica em uma das extremidades de cada tecido, está a pequena aranha, que faz a sua caminhada dessa maneira. Isso corresponde ao estado mais móvel das larvas, quando as jovens aranhas voam em nossos "fios de outono", algumas das quais na velhice nem formam mais nenhuma teia.

Os dispositivos que facilitam os grãos de semente e favorecem seu voo de tipo paraquedas, tais como os que encontramos nos frutos dos olmos, bordos e muitas coníferas, muitas vezes servem mais para distribuição uniforme nos espaços adjacentes à área de origem do que ao transporte a amplas distâncias. 0 fato das árvores que habitam as montanhas do sul da Europa, tais como em Ahorne e Tannen, estejam ausentes nas altas montanhas da África, comprova a baixa capacidade de migração de suas sementes, apesar de seu dispositivo de voo. Isso também é válido para muitas plantas com coroinhas de semente constituídas de pelos e folhinhas leves, que geralmente não são mais difundidas do que plantas relacionadas sem esses dispositivos.

Os manguezais e outros residentes [Bürger] das florestas litorâneas tropicais que chamamos de restinga mostram a propagação por correntes oceânicas de maneira mais proeminente. Sua difusão geográfica mostra uma afinidade próxima em um único e mesmo mar. As formas indianas ainda são muito comuns nas Seicheles e em Madagascar, todavia, consideravelmente escassas na África Oriental. Na África Ocidental ocorrem apenas duas espécies, mas, em compensação, ali as afınidades com as Índias Ocidentais são então predominantes. As espécies autóctones que ocorrem na África Oriental [p. 19 / 121] têm frutos à deriva que resistem à água do mar. Muitas sementes de planta perdem de fato seu poder de germinação na água do mar mas, de acordo com as investigações de Marten, de 98 sementes diferentes 18 mantiveram seu poder de germinação após 42 dias na água do mar.

Também no caso dos animais, a concordância de algumas regiões de difusão com a região banhada por uma corrente marítima joga a favor do transporte por correntes marítimas. Se o gênero de focas Pelagius, que antigamente se acreditou estar ligado ao Mediterrâneo, ocorre nas costas das Canárias e Madeira, ou os leões-marinhos-da-Patagônia (Otaria) no Oceano Pacífico partindo da região antártica se disseminam para o norte nas margens banhadas pelas correntes frias, a despeito dos leões-marinhos de Galápagos pertencerem a um gênero diferente do californiano, vê-se, deste modo, o efeito das correntes frias e águas costeiras do Oceano Pacífico Oriental, atravessado pela corrente quente do Panamá.

No litoral, a corrente litorânea composta de mil ondas terrestres transporta animais e seus germes por longos trechos. Por acaso, essa migração é mais precisamente controlada, como a de Littorinea littorea, que lentamente segue seu caminho para o norte ao longo da costa atlântica da América do Norte, como observado pela primeira vez em 1869. Desde então, ela penetrou no estuário de Long Island em Nova York. A mya arenaria migra para várias direções na costa do Pacífico da América do Norte, tendo sido trazida até ali provavelmente com ostras. 0 mesmo movimento também atinge as ilhas próximas. Provavelmente ele não é totalmente desvinculado de 
uma difusão tão peculiar, assim como mostra uma quantidade de formas de plantas nas margens do Golfo da Biscaia das Astúrias até a Bretanha e, em seguida, por todo o caminho para a Irlanda.

[p. 20 / 122] A madeira à deriva oferece os mais claros indícios de transporte pelas correntes marítimas. As correntes marítimas, das quais não se conhecia muito antes da exploração do Oceano Ártico na Sibéria e no leste da Groenlândia, foram exploradas a partir da distribuição das florestas siberianas nas costas da Groenlândia. Estas provavelmente fizeram a fronteira marítima do norte da Groenlândia e, portanto, sua natureza insular, antes que as conhecêssemos. As sedimentações nas costas do norte da Noruega pertencem às primeiras evidências da Corrente Ocidental do Atlântico Norte. 0 arquipélago de Lofoten, enquanto ilhas posicionadas adiante, e a costa de Troms $\varnothing$ recebem o máximo disso. Entre os bosques, o lariço canadense é o mais fortemente representado, em troncos de até 10 metros de comprimento, depois o pinus strobus, entre outros; dentre as sementes também ocorre o coco e a cabaça, a há muito conhecida entada scandens, a guilandina, em suma, [sementes] tropicais. A madeira à deriva está em declínio correspondente à regressão das florestas que outrora a abasteciam em massa, já os outros objetos à deriva ainda cruzam pouco a pouco os oceanos. Aderindo às madeiras à deriva e às quilhas de navios, todos os crustáceos, ascídias, vermes, Pholadidæ e bivalvias, gerações de medusas polipóides e briozoários fazem viagens oceânicas. A famosa rêmora [família Echeneidæ] é um peixe conhecido por ser dotado de ventosa especial na cabeça para poder se manter fixo. Por isso [chamado] Schiffshalter ${ }^{8}$.

A corrente equatorial sul do Oceano Índico, juntamente com a sua continuação, a corrente de Mascarenhas, trouxe a Port Elizabeth, em 1886 e 1887, grandes massas de pedra-pomes, que possivelmente provieram da erupção do Krakatoa. Com elas chegaram diferentes seres vivos do arquipélago malaio: Pelamys [atum] bicolor, uma cobra aquática venenosa, várias arraias grandes, numerosos belones [peixe-agulha]. 0 fruto sedimentado de uma myrtaceæ se desenvolveu arraigando-se como a barringtonia asiática. [p. 21 / 123] De fato, após a explo-

${ }^{8}$ Schiffshalter, palavra composta por Schiff, que quer dizer genericamente "embarcação", e Halter, substantivo que remonta ao verbo halten, cujo significado pode ser "segurar", "aderir", "agarrar", "parar", "reter", "manter", apresenta aqui provavelmente duplo sentido, uma vez que tal peixe assim apelidado não só se segura, se agarra no casco das embarcações, como também, tal como historicamente ficou conhecido por ter este comportamento acima mencionado, acaba por "reter", "segurar" as próprias embarcações em seu movimento, atuando como uma espécie de freio por aumentar o atrito do casco com a água e, com isso, impedindo a embarcação de navegar em velocidade maior. A propósito, seu próprio nome vulgar "rêmora" vem do latim, onde o prefixo "re-", partícula intensificadora, reforma o sufixo "-mora", cujo significado remonta a "demora", "atraso". [N.T.] são do Krakatoa, nas proximidades do palco do acontecimento, vastas quantidades de pedra-pomes flutuavam no Oceano Índico, entre as quais foram encontradas árvores de mata ciliar desenraizadas com animais terrestres sobre elas, até mesmo répteis.

Tais fenômenos foram vistos em outros mares e seria uma bela tarefa, em algum momento, reunir as informações mais importantes dos diários de bordo a esse respeito. Apenas um exemplo: no verão de 1892, uma ilha flutuante, um pedaço de terra unido por raízes das árvores de cerca de 1.000 metros quadrados foi observado várias vezes. Ela foi acompanhada de $39,5^{\circ}$ a $45^{\circ}$ de latitude a norte e de $65^{\circ}$ a $43^{\circ}$ de longitude a oeste, portanto, até $\mathrm{o}$ alto das Ilhas dos Açores e a caminho da Corrente do Golfo. Ao mesmo tempo, lembra-se do fato peculiar de que todos os marsupiais que ultrapassam as fronteiras da área de difusão australiana continental, são habitantes que escalam árvores e que, assim, poderiam se disseminar em troncos de árvore à deriva. Dessa forma, os caracóis terrestres que se agarram muito fortemente à terra também podem cruzar estuários. Semper relata que, entre as espécies notavelmente numerosas das Filipinas, as mais difundidas são aquelas com pálpebras e que vivem em fendas de terra ou árvore.

Os efeitos biogeográficos do gelo à deriva superam os de qualquer outro meio natural de transporte em virtude da capacidade de carga do conjunto, das dispersões e da mobilidade, que são inerentes ao gelo. Nos mares gelados do Norte acrescenta-se ainda, favorecendo essa dispersão, o rearranjo do mar com grandes terras e o estabelecimento de ilhas. 0 urso polar e a raposa polar já carregam em seu nome a alusão a uma certa familiaridade com o gelo e, de fato, são hóspedes muito frequentes também sobre o gelo à deriva, de tal sorte que não se pode duvidar de seu transporte sobre gelo à deriva de uma terra e de uma ilha a outra. Se a [p. 22 / 124] expedição austríaca viu o urso polar aparecer na ilha Jan Mayen apenas no inverno, isso seria apenas uma prova de que ele viaja com o gelo. Então ele aparece na Ilha dos Ursos, na Islândia, na ilha da Terra Nova e na ilha de Wrangel, e foi visto anteriormente no norte da Noruega. Parry encontrou o urso polar no mar ao norte de Spitsbergen, a $82,5^{\circ}$ de latitude norte. Sobre a raposa polar, a habilidade com a qual ela salta de um bloco de gelo a outro é famosa. O Holmes e as ilhas nos quais ela [raposa] se empilha, ela [raposa] só pode ter alcançado no gelo. Também o lobo foi visto no gelo à deriva e Heuglin acreditou que a rena e o dicrostonyx [um gênero de roedor] haviam sido impelidos a Spitsbergen no gelo. Entretanto, a migração da rena pelo gelo deve ser rejeitada, pois ela é também um dos antigos habitantes da Europa.

A migração de um ser vivo na esteira de um outro está 
relacionada ao transporte passivo. Os percursos de ruminantes que migram são sempre seguidos nas estepes da África do Sul e da América do Norte pelos predadores; as raposas polares cercam os percursos dos lemingues assim como os peixes predadores acompanham os grandes percursos migratórios dos arenques e atuns. Talvez algo semelhante seja o acontecimento cada vez mais frequente e várias vezes afirmado do furão no "ano do hamster".

Organismos mais fracos se associam de maneira autônoma aos [organismos] mais fortes e em sua esteira conquistam espaços que eles jamais teriam conseguido adquirir com sua própria força. A propagação da ratazana (Mus decamanus) nos mostra não apenas essa dependência, mas até mesmo um alcance além da região de distribuição do homem. Quase nenhum outro animal manifesta desse modo a conexão com o ser humano em sua distribuição; mas esse rato doméstico se disseminou para as ilhas desertas de Saint Paul e Amsterdam, as quais ainda estão fora do ecúmeno. De modo semelhante, [p. 23 / 125] o rato da neve (Arvicola nivalis) atravessa a fronteira de fogo nos nossos Alpes e passa sua vida em grandes altitudes, onde até as pastagens alpinas não são mais cultivadas. Muito mais distante é a conexão com o ser humano da bela-dama polyphaga [um tipo de besouro], que vive principalmente de ervas daninhas, e ainda assim sua região coincide bem próxima à do homem.

Por fim, animais maiores servem simplesmente como meio de transporte aos menores. Os parasitas que migram no ou dentro de seus "hospedeiros" constituem um grande grupo próprio. Desde que Darwin chamou a atenção para o transporte de sementes de plantas e animais em membranas, bicos, línguas e plumagem de aves aquáticas, nesses órgãos foram encontrados ovos dos mais variados animais inferiores, diatomáceas, estatoblastos de plumatella repens, cascos de ostracodes, cladoceras, philodina, rizópodes e muitos outros. Se, enquanto único sapo de genuíno tipo americano Bufo dialophus, está presente no Havaí, mas não em outros lugares na Polinésia, pode-se bem pensar na transferência de sua oveira por pássaros que migram periodicamente entre a América do Norte e as ilhas havaianas. Através da lã ou do pelo dos mamíferos, as sementes das plantas que aí ficam presas, são deportadas. Willkomm fala de um grande número de plantas que são transferidas pelos rebanhos de ovelha das pastagens de inverno de planícies da Extremadura e da Andaluzia para o planalto mais elevado de Castela, Leão, Navarra e para as montanhas. 0 caminhar morro acima da flora e fauna fertilizantes de rebanhos que pastam pode ser encontrado em todas as montanhas com agricultura alpina. Numerosas plantas de estepe foram naturalizadas na flora montanhosa da África Oriental pelos rebanhos dos nômades. Darwin chegou até mesmo a aceitar como possível [p. 24 / 126] que a peculiar proliferação de pequenos roedores sobre alguma ilha no arquipélago de Chonos [no sul do Chile] poderia ser atribuída à deportação através de grandes animais de rapina que trazem vivas em seus ninhos essas pequenas criaturas. 